\title{
A mechanism for TAFs in transcriptional activation: activation domain enhancement of TFIID-TFIIA-promoter DNA complex formation
}

\author{
Paul M. Lieberman ${ }^{1}$ and Arnold J. Berk ${ }^{2}$ \\ ${ }^{1}$ Roche Institute of Molecular Biology, Nutley, New Jersey 07110-1199 USA; ${ }^{2}$ Molecular Biology Institute, Department \\ of Microbiology and Molecular Genetics, University of California, Los Angeles, California 90024-1570 USA
}

\begin{abstract}
TATA-binding protein (TBP)-associated factors (TAFs) in TFIID are required for activator proteins to stimulate transcription, but the mechanism by which TAFs function is poorly understood. To study how TAFs participate in transcriptional activation by the Epstein-Barr virus activator $\mathrm{Zta}$, we used agarose gel electrophoresis and DNase I footprinting to compare transcription complex assembly in reactions with either TFIID or TBP in the presence and absence of wild-type Zta or a deletion of Zta lacking its activation domain. A stable complex of promoter DNA with Zta, TFIIA, and TFIID rapidly formed on a template with Zta-binding sites. Zta stimulation of stable complex formation required TAFs as well as the Zta activation domain and TFIIA. The Zta activation domain also induced a TAF-dependent DNA-protein interaction near and downstream of the transcription start site. Stable complexes formed within 1 min supported activated transcription when RNA polymerase II and the remaining general transcription factors were subsequently added. This rapid assembly of a stable Zta-TFIIA-TFID-promoter complex is probably a significant component of the mechanism by which TAFs and the Zta activation domain cooperate to stimulate transcription.
\end{abstract}

[Key Words: TAFs; TFIID; transcriptional activation; promoter DNA; transcription complex]

Received February 4, 1994; revised version accepted March 22, 1994.

Transcription of protein-coding genes in eukaryotes is regulated by interactions between a large preinitiation complex assembled at the transcription start site and activators and repressors bound to DNA tens to thousands of base pairs away (Ptashne and Gann 1990; Roeder 1991; Gill and Tjian 1992). The preinitiation complex is an elaborate structure composed of general transcription factors plus RNA polymerase II. It consists of $>40$ polypeptides with a total molecular mass in excess of 2 million daltons, nearly the size of a prokaryotic ribosome (Zawel and Reinberg 1993). Preinitiation complex assembly on a promoter containing a TATA box has been studied extensively in reactions with yeast TATA boxbinding protein (TBP) in the absence of regulatory proteins (for review, see Zawel and Reinberg 1993). The preinitiation complex forms in an ordered multistep pathway starting with the binding of TBP to the TATA box, followed by TFIIB, a complex of TFIIF and RNA polymerase II, TFIIE, TFIIH, and TFIIJ. TFIIA can add to the complex at any time following TBP binding. TFIIA is not required for basal transcription using TBP and highly purified factors (Parvin et al. 1992; Ma et al. 1993), but it is required for activated transcription (Ma et al. 1993), and the yeast genes that encode TFIIA are essential for viability (Ranish et al. 1992).

The protein that interacts with the TATA box is called TFIID. In higher eukaryotes, TFIID is an $\sim 750-\mathrm{kD}$ multisubunit protein composed of the TATA box-binding subunit TBP and several tightly associated polypeptides called TAFs (for review, see Hernandez 1993). Whereas the isolated TBP subunit will support "basal" transcription in vitro, the TAFs associated with TFIID are required for activator proteins to stimulate transcription. In this paper we refer to the TFIID complex of TBP plus TAFs as "holo-TFIID" to clearly distinguish it from the isolated TBP subunit and partially purified fractions of TFIID that may contain additional factors.

Several general transcription factors have been implicated as "targets" of activator proteins (for review, see Greenblatt 1991; Gill and Tjian 1992). Early work indicated that activators influence TFIID binding to the TATA box (Sawadogo and Roeder 1985; Abmayr et al. 1988; Horikoshi et al. 1988a,b). Consistent with this model, several transcriptional activators have been found to bind directly to the isolated TBP subunit of holo-TFIID (Stringer et al. 1990; Horikoshi et al. 1991; 
Lee et al. 1991; Lieberman and Berk 1991). The importance of these activator-TBP interactions has been demonstrated for VP16 and E1A. Point mutations in these activators that reduce TBP binding in vitro also reduce activation function in vivo (Ingles et al. 1991; Lee et al. 1991; Geisberg et al. 1994). E1A and p53 have also been shown to bind to TBP when it is associated with TAFs in the holo-TFIID complex (Boyer and Berk 1993; Liu et al. 1993). The Spl activator also interacts directly with holo-TFIID, but it binds to a TAF rather than the TBP subunit (Hoey et al. 1993). The VP16 activator may interact with holo-TFIID by binding to both TBP and a TAF. Whereas one activation subdomain of VP16 binds TBP specifically (Ingles et al. 1991), another binds to a TAF (Goodrich et al. 1993). TFIIB also binds directly to the VP16 activation domain and is stably and functionally retained at promoter templates that bind VP16 and TFIID (Lin and Green 1991). The functional significance of this interaction was demonstrated in studies with a TFIIB deletion mutant that fails to bind the VP16 activation domain and has lost the ability to support activated, but not basal, transcription (Roberts et al. 1993). Finally, TFIIA has been implicated as a functional target of GAL4-AH and Zta, which appear to overcome the slow assembly of a TFIIA-TFIID-promoter complex (Wang et al. 1992; Chi and Carey 1993).

Some activator proteins also require a coactivator or adapter molecule in addition to the general transcription factors to stimulate initiation by the preinitiation complex (Flanagan et al. 1991; Meisterernst et al. 1991). Several genes isolated in yeast have the properties of adapter molecules or coactivators, including ADA2 for VP16 (Berger et al. 1992), SWIl for the glucocorticoid receptor (Yoshinaga et al. 1992), and SRB2, which was shown to bind TBP directly in vitro (Koleske et al. 1992). Whether these coactivators or adapters are components of a general preinitiation complex or are auxiliary proteins required only for stimulation by certain subclasses of activators remains to be fully elucidated. In addition, core histones and histone $\mathrm{Hl}$ have been shown to act as repressors that can be derepressed by the action of activator proteins (Workman et al. 1991; Croston et al. 1991).

In earlier work we reported that the activation domain of the Epstein-Barr virus transcriptional activator $\mathrm{Zta}$ binds directly to TBP and decreases the dissociation rate of TBP from a TATA box (Lieberman and Berk 1991). Although the interaction of TBP with Zta may reflect an important component of the Zta activation mechanism, it cannot explain all of $Z$ ta function. Like other activator proteins, Zta-activated transcription requires that TBP be associated with TAFs (Zhou et al. 1992). The TAFs have been proposed to act as a molecular bridge between the activator and TBP (Dynlacht et al. 1991; Pugh and Tjian 1992), but the function of the TAFs must entail more than simply mediating the physical association of activators like $\mathrm{Zta}$ with $\mathrm{TBP}$, because $\mathrm{Zta}$ can associate directly with TBP in the absence of the TAFs.

As a first step in addressing the question of how TAFs function with the $\mathrm{Zta}$ activation domain to stimulate transcription, we examined the ability of $Z$ ta and TAFs to influence the assembly of a preinitiation complex. We used both gel electrophoretic mobility-shift assays (EMSAs) and DNase I footprinting to analyze DNA-protein complex formation. To examine the potential function of the TAFs in Zta-mediated transcriptional activation, we compared complex formation in the presence of either TBP (which lacks TAFs) or holo-TFIID (which contains TAFs). We report that $\mathrm{Zta}$ affects preinitiation complex formation at a very early step in the assembly pathway, namely the formation of a TFIIA-TFIID-promoter complex, and that this effect is dependent on both the TAFs and the $\mathrm{Zta}$ activation domain. In addition, we observe evidence for an activation domain-induced interaction between TAFs and promoter DNA in the region near and downstream from the transcription start site that may influence subsequent steps in preinitiation complex assembly and transcription initiation.

\section{Results \\ Zta stimulates the assembly of a holo-TFIID- TFIIA-promoter DNA complex}

To test whether the Zta activator influences an early step in preinitiation complex assembly, we used TFIID purified $\sim 15,000$-fold to near homogeneity from HeLa cells expressing an epitope-tagged TBP (holo-TFIID; Zhou et al. 1992), purified recombinant TFIIB (Ha et al. 1991), TFIIA partially purified from HeLa cells, and the $\mathrm{Z}_{7} \mathrm{E}_{4} \mathrm{~T}$ promoter containing seven $\mathrm{Zta}$-binding sites upstream from the adenovirus E4 TATA box (Carey et al. 1992; Fig. 1) to measure complex assembly in an EMSA. We found that EMSA conducted in $1.4 \%$ agarose gels containing $5 \mathrm{mM} \mathrm{Mg}^{2+}$ was suitable for resolving the very large protein-DNA complexes of interest. One unit of $\mathrm{Zta}$ (see Materials and methods) shifted all of the free probe into a Zta-DNA complex of rapid mobility (Fig. 2A, lane 2). DNase I footprinting showed that all seven Zta-binding sites were saturated (Fig. 3A, lanes 5,6; data not shown for the distal binding sites). One unit of holoTFIID shifted $10 \%$ of the input probe (Fig. 2A, lane 3).

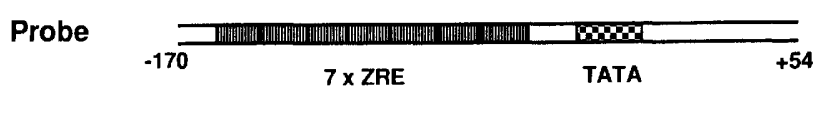

Activator

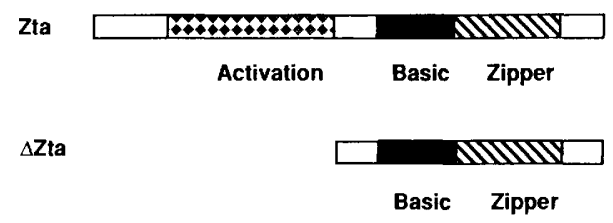

Figure 1. The $\mathrm{Z}_{7} \mathrm{E}_{4} \mathrm{~T}$ promoter and $\mathrm{Zta}$ activator. The $\mathrm{Z}_{7} \mathrm{E}_{4} \mathrm{~T}$ promoter probe contains sequences from -170 to +54 and was used in all agarose gel EMSA and DNase I footprinting experiments. The activator proteins used in these experiments were the full-length 240 -amino-acid $\mathrm{Z}$ ta protein or the amino-terminal deletion mutant $\Delta \mathrm{Zta}$ that lacks the transcriptional activation domain present in residues 1-140. 


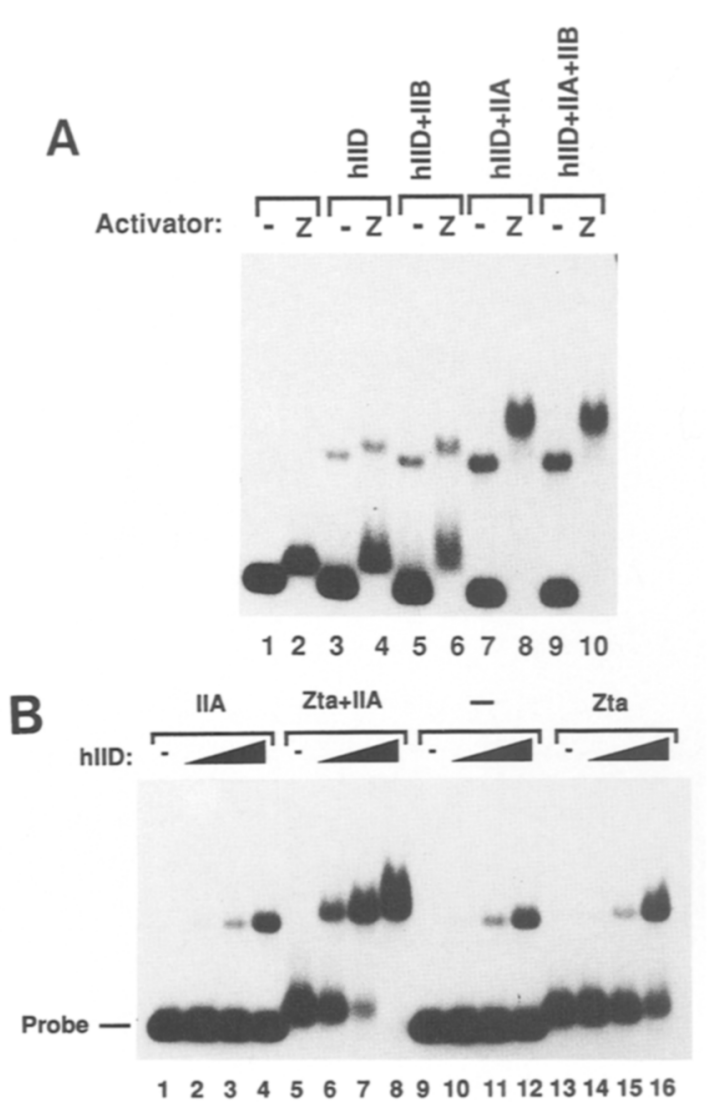

Figure 2. Zta stimulates the assembly of a TFIIA-TFIID promoter complex. $(A) \mathrm{Mg}^{2+}$ agarose EMSA of Zta-induced complex formation. One unit each of holo-TFIID (hIID), TFIIA (IIA), and TFIIB (IIB) were incubated (as indicated above each lane) with the $\mathrm{Z}_{7} \mathrm{E}_{4} \mathrm{~T}$ promoter probe for $60 \mathrm{~min}$ at $30^{\circ} \mathrm{C}$. One unit of $Z_{t a}$ was added to the reactions analyzed in the even-numbered lanes. $(B)$ Binding reactions contained 0 (lanes 1,5,9,13), 0.1 (lanes 2,6,10,14), 0.3 (lanes 3,7,11,15), or 1.0 (lanes $4,8,12,16$ ) units of holo-TFIID and one unit each of TFIIA and Zta as indicated and were incubated at $30^{\circ} \mathrm{C}$ for 20 min before electrophoresis in a $\mathrm{Mg}^{2+}$ agarose gel.

Holo-TFIID did not shift control probes that lacked a TATA box and shifted several probes prepared from different TATA box-containing promoters to a similar position in the gel (not shown). Addition of $\mathrm{Zta}$ did not increase the number of templates bound by holo-TFIID significantly, but it did result in a mobility shift expected for the simultaneous binding of $\mathrm{Zta}$ and holoTFIID (Fig. 2A, lane 4).

Addition of one unit of TFIIA increased the amount of shifted probe compared with holo-TFIID alone (Fig 2A, lanes 3,7$)$. This is similar to the previously reported ability of TFIIA to stimulate the amount of complex observed with yeast TBP in a polyacrylamide gel EMSA (Hahn et al. 1989). In this agarose gel system, addition of TFIIA did not alter the mobility of the holo-TFIID complex. Despite this lack of change in mobility, it was clear from DNase I footprinting that TFIIA does bind to the holo-TFIID-promoter DNA complex. Sufficient holo-
TFIID was used in a footprinting assay to produce clear protection of the TATA box region (Fig. 3A, lanes 3-6). Under these conditions, addition of the TFIIA fraction extended the footprint in the upstream direction (lanes 4,61 , as reported previously for TFIIA in footprinting studies with yeast TBP (Buratowski et al. 1989).

Significantly, incubation of the probe with Zta, TFIIA, and holo-TFIID shifted all of the probe into a slow mobility complex (Fig. 2A, lane 8). No effect of Zta was observed on a probe lacking Zta-binding sites (data not shown). Incubation of Zta with holo-TFIID and TFIIB did not have this effect (lane 6). Similarly, addition of TFIIB to the Zta-holo-TFIID-TFIIA (Z-D-A) complex did not result in any further change in the mobility of the Z-D-A complex (lane 10). This preparation of TFIIB decreased the mobility of a TBP-TFIIA-TATA box complex in polyacrylamide gel EMSA, as expected (Buratowski et al. 1989). Consequently, we believe that TFIIB does bind to the Z-D-A complex but that it does not produce a detectable change in the mobility of the complex in this agarose EMSA system. As discussed below, in this gel system, the mobilities of complexes containing TFIID are largely unaffected by changes in molecular weight. However, this gel system was valuable for observing the dramatic effect of $\mathrm{Zta}$ on formation of the holo-TFIID-TFIIA-promoter DNA complex (lane 8). This effect of $\mathrm{Zta}$ was observed over a range of holoTFIID concentrations (Fig. 2B). Holo-TFIID of 0.3 unit shifted only a small fraction of the probe in the presence of TFIIA (lane 3), whereas in the presence of both Zta and TFIIA, most of the probe was shifted (lane 7).

\section{Detection of the Z-D-A complex by DNase I footprinting}

Figure 2 shows that $Z$ ta stimulates complex formation by holo-TFIID and TFIIA as assayed by agarose gel EMSA. To confirm this result, we analyzed complex formation by DNase I footprinting (Fig. 3B). One unit of holo-TFIID, which shifts nearly all of the probe into a slow mobility EMSA complex in the presence of $Z$ ta and TFIIA (Fig. 2), also generated a clear footprint over the TATA box in the presence of $\mathrm{Zta}$ and TFIIA (Fig. 3B, lane 6). In contrast, little protection was observed in the absence of $\mathrm{Zta}$ (cf. lane 5 with the no protein controls in lanes 1 and 11). Similarly, in the absence of TFIIA, Zta did not stimulate protection over the TATA box (cf. lanes 2 and 3). Consequently, the results of the DNase I footprinting analysis were consistent with the agarose gel EMSA. We conclude that Zta stimulates the formation of a holo-TFIID-TFIIA-promoter complex. We further conclude that the ability of $\mathrm{Zta}$ to stimulate complex formation requires TFIIA.

\section{$Z$ ta stabilizes the $Z-D-A$ complex during gel electrophoresis}

The complex between yeast TBP and a TATA box dissociates with a half-life of 90-135 min during EMSA in a 

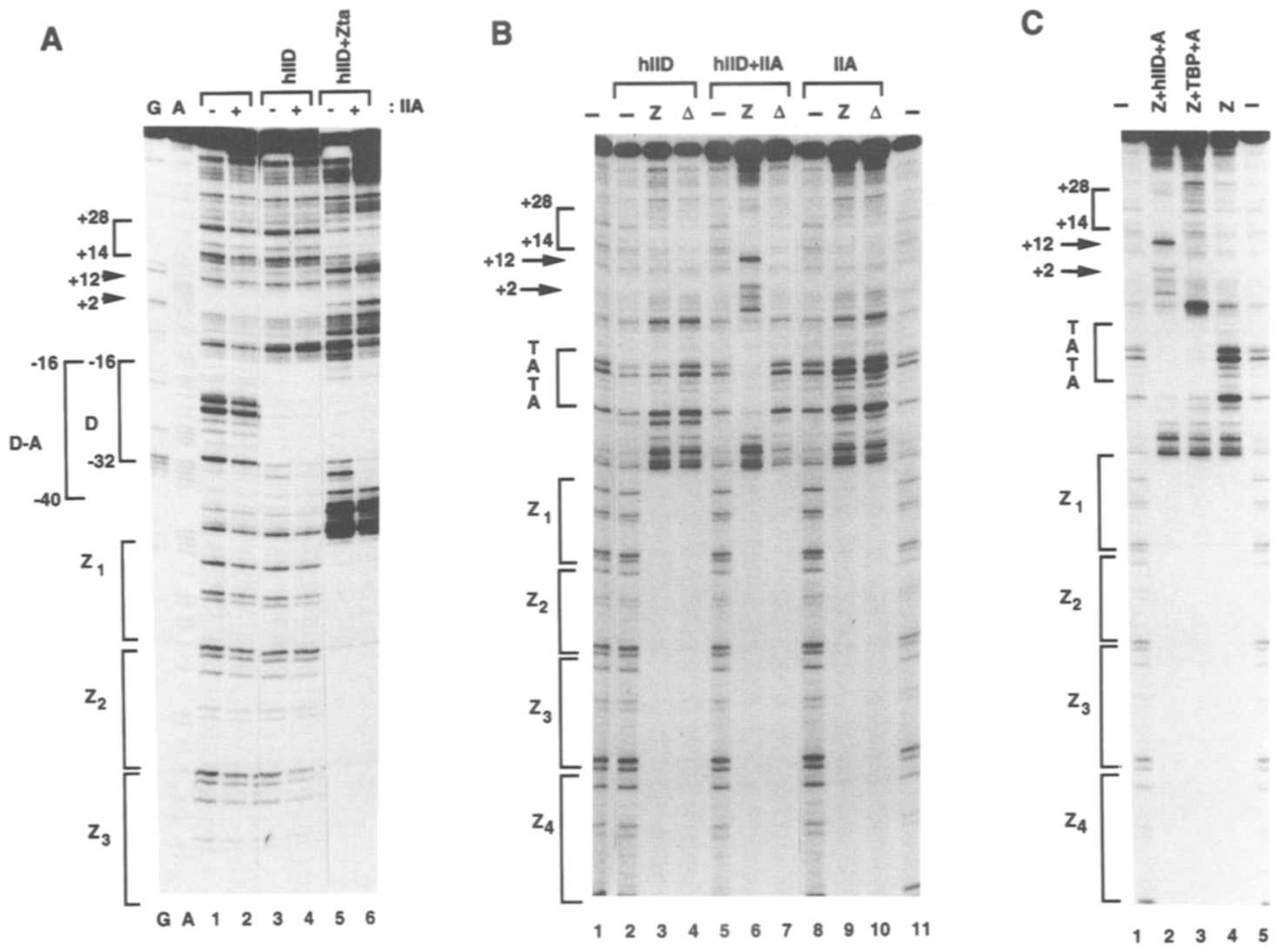

Figure 3. DNase I footprinting of DNA-protein complexes. (A) Maxam-Gilbert G and G+A sequencing reactions are in lanes labeled $G$ and A, respectively. Binding reactions contained 1 unit of TFIIA (lanes 2,4,6), 8 units of holo-TFIID (lanes 3-6), and 1 unit of Zta (lanes 5,6). Lane 1 shows the DNase I pattern in the absence of added proteins. $(B)$ Binding reactions contained 1 unit each of holo-TFIID (hIID), TFIIA (IIA), Z ta (Z), or $\Delta \mathrm{Zta}(\Delta)$, as indicated at the top. No Zta or $\Delta \mathrm{Zta}$ was added to the reactions shown in lanes 2, 5, and 8 . Lanes 1 and 11 show the DNase I pattern in the absence of added proteins. The region of the TATA box and the Zta-binding sites are indicated by brackets at left. DNase I hypersensitive sites at +2 and +12 (indicated by arrows) and a region of protection from +14 to +28 (indicated by a bracket) induced by Zta, holo-TFIID, and TFIIA are indicated at left. Hypersensitive sites were also apparent at -6 and $-2 .(C)$ Binding reactions contained no added protein (lanes 1,5), 1 unit each of Zta, holo-TFIID, and TFIIA (lane 2), 1 unit each of $Z$ ta and TFIIA plus sufficient recombinant human TBP to produce a clear footprint over the TATA box region (lane 3), and 1 unit of $Z$ ta (lane 4).

polyacrylamide gel (Hoopes et al. 1992). Consequently, the intensity of the TBP-DNA complex band observed in an EMSA is a function of both the amount of complex initially formed during the binding reaction and the extent of dissociation during electrophoresis. To determine whether stabilization of the DNA protein complex contributed to the increase in EMSA complex observed following incubation of probe with $\mathrm{Zta}$, holo-TFIID, and TFIIA (Fig. 2), we performed an experiment analogous to one reported by Hoopes et al. (1992) (Fig. 4). Sufficient holo-TFIID was added to the binding reaction to associate with all of the probe in the absence of added $\mathrm{Zta}$ and TFIIA, as determined by DNase I footprinting of half the sample (Fig. 4A, lane 2). Parallel binding reactions contained the same amount of holo-TFIID and TFIIA (lane 3) and holo-TFIID, TFIIA, and Zta (lane 4). The other half of each sample was subjected to agarose gel EMSA (Fig. 4B). Even though most of the probe was initially bound by holo-TFIID alone, as demonstrated by virtually complete protection of the TATA box region from DNase I digestion (Fig. 4A, lane 2), less than half of the probe appeared in the retarded complex observed by EMSA /Fig. 4B, lane 2). This indicates that the holo-TFIID-promoter DNA complex partially dissociated during electrophoresis. TFIIA stabilized the complex somewhat, because more of the probe appeared in the retarded complex (lane 3). However, after incubation with Zta, holo-TFIID, and TFIIA, nearly all of the probe remained in the retarded complex (lane 4). Consequently, in addition to stimulating complex formation as observed in the DNase I footprinting experiment of Figure 3B, $\mathrm{Zta}$ increases the stability of the holo-TFIID-TFIIA-promoter complex so that it does not dissociate significantly during EMSA. On the basis of the results of Figures 2, 3B, and 4, we conclude that $\mathrm{Zta}$ stimulates the formation of a stable Z-D-A complex on promoter DNA containing Zta-binding sites. Agarose gel EMSA is a convenient assay for the detection of this stable Z-D-A complex. 
A

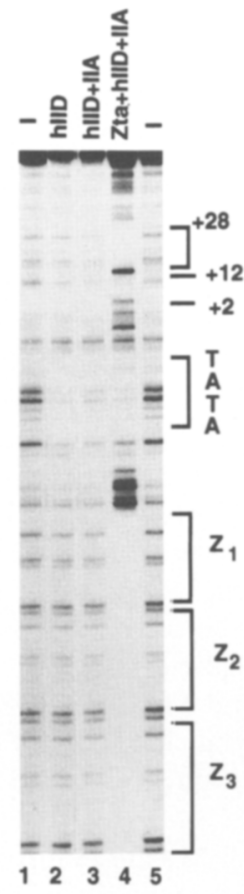

B

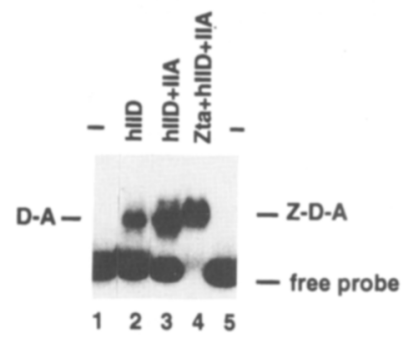

Figure 4. The Zta-TFIID-TFIIA-promoter complex is stable during gel electrophoresis. Binding reactions contained no protein (lanes 1,5), 8 units of holo-TFIID (lanes 2-4), 1 unit of TFIIA (lanes 3,4), and 1 unit of Zta (lane 4). Half of the reaction was analyzed by DNase I footprinting $(A)$ and the other half by agarose gel EMSA with an electrophoresis time of $3 \mathrm{hr}$.

The Zta activation domain is required to stimulate $Z-D-A$ stable complex formation

Zta-mediated transcriptional activation requires the amino-terminal activation domain of Zta (Giot et al. 1990; Lieberman and Berk 1991; Flemington et al. 1992). To test whether the Zta stimulation of stable complex formation requires the $Z_{\text {ta }}$ activation domain, we utilized the $\mathrm{Zta}$ amino-terminal truncation mutant $\Delta \mathrm{Zta}$ (Fig. 1). $\Delta Z$ ta does not have significant transcriptional activity in vitro or in vivo but binds DNA with equal or higher affinity than does full-length Zta. Although fulllength $Z$ ta has greater molecular mass than $\Delta Z \mathrm{ta}$, the Zta-DNA complex migrated with faster mobility than the smaller $\triangle \mathrm{Zta}$-DNA complex in the $\mathrm{Mg}^{2+}$ agarose EMSA (Fig. 5A, lanes 2,3). We presume that this reflects a more compact structure of the full length $Z$ ta in the presence of $\mathrm{Mg}^{2+}$ ion compared with the structure of
$\Delta$ Zta. As observed in Figure 2A, TFIIA modestly increased the amount of complex observed compared with holo-TFIID alone (Fig. 5A, lanes 4,7). As before, Zta strongly stimulated complex formation in the presence of both holo-TFIID and TFIIA (lane 8) but not in the presence of holo-TFIID alone (lane 5). However, $\Delta \mathrm{Zta}$ did not stimulate complex formation at all (lane 9). Similar results were observed by DNase I footprinting (Fig. 3B, cf. lanes 6 and 7). We conclude that the ability of Zta to stimulate formation of a stable $\mathrm{Z}-\mathrm{D}-\mathrm{A}$ complex requires the $\mathrm{Zta}$ activation domain.

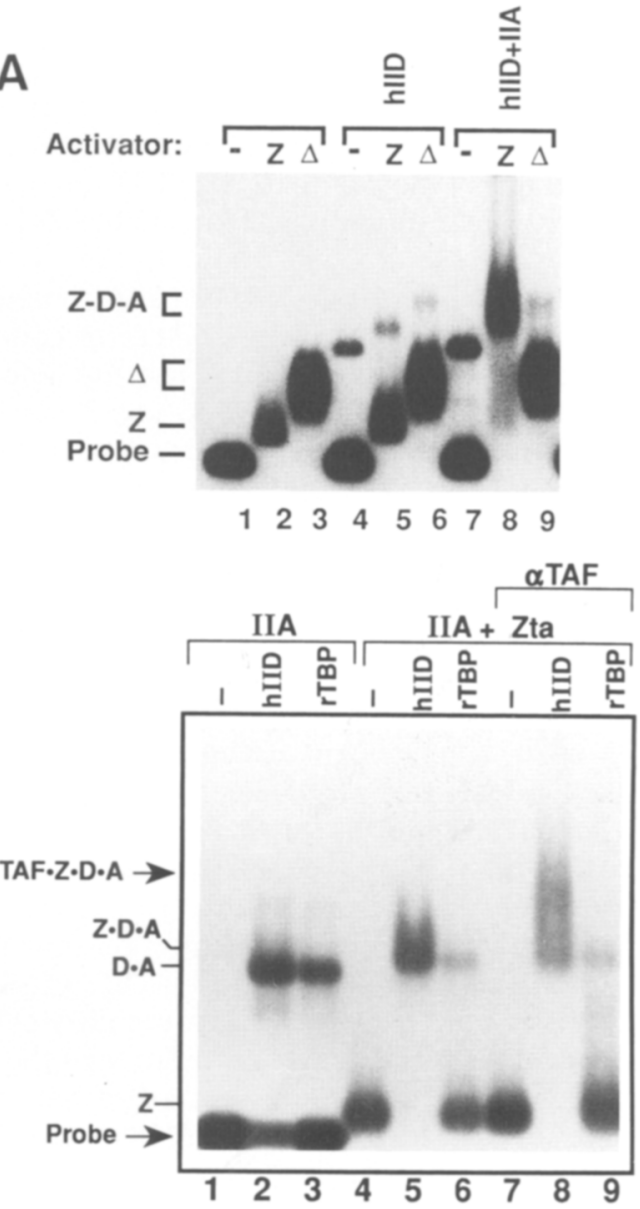

Figure 5. The $\mathrm{Zta}$ activation domain and TFIID TAFs are required to stimulate formation of the Z-D-A stable complex. $(A)$ One unit of Zta (lanes 2,5,8) or $\Delta \mathrm{Zta}$ (lanes $3,6,9)$ was incubated with probe only (lanes $1-3$ ), or with probe and 1 unit of holoTFIID (lanes 4-6), or with probe and 1 unit each of holo-TFIID and TFIIA (lanes 7-9). Products were analyzed by agarose gel EMSA. Lane 1 shows probe alone. The position of complexes formed by $Z$ ta $(Z), \Delta Z$ ta $(\Delta)$, and $Z$ ta, holo-TFIID, and TFIIA $(\mathrm{Z}-\mathrm{D}-\mathrm{A})$ are indicated at left. $(B)$ Binding reactions contained 1 unit of TFIIA (lanes 1-3), 1 unit each of TFIIA and $\mathrm{Zta}$ (lanes 4-9) plus 5 units of holo-TFIID (lanes $2,5,8$ ), or $10 \mathrm{ng}$ of recombinant human TBP (lanes 3,6,9). After incubation for $60 \mathrm{~min}$ at $30^{\circ} \mathrm{C}, 1 \mu \mathrm{l}$ of mouse anti-TAF 250 (Ruppert et al. 1993) was added to reactions shown in lanes $7-9$, and incubation continued for $15 \mathrm{~min}$ at $25^{\circ} \mathrm{C}$ before analysis of all samples by agarose gel EMSA. 
TAFs are required for Zta stimulation of stable complex formation

TFIID TAFs are required for $\mathrm{Zta}$ to stimulate transcription (Zhou et al, 1992). Consequently, we examined whether the ability of $Z$ ta to stimulate formation of the Z-D-A stable complex requires the TAFs in holo-TFIID. Stable complex formation was analyzed by agarose gel EMSA following incubation of probe with TFIIA and either holo-TFIID or recombinant TBP plus or minus Zta (Fig. 5B). Although Zta stimulated stable complex formation in the presence of holo-TFIID and TFIIA, resulting in the retardation of all the input probe (lane 5), Zta did not stimulate stable complex formation when holoTFIID was replaced with TBP (lane 6). DNase I footprinting assays also failed to demonstrate any significant effect of Zta on the binding of TBP to the TATA box in the presence or absence of TFIIA (data not shown). We conclude that one or more of the TFIID TAFs are required for Zta to stimulate formation of the stable Z-D-A complex.

The mobility of the holo-TFIID-TFIIA complex in this gel system was the same as the TBP-TFIIA complex (Fig. $5 \mathrm{~B}$, lanes 2,3 ). This was surprising because holo-TFIID is $\sim 750 \mathrm{kD}$, whereas TBP is only $38 \mathrm{kD}$. To test the unlikely possibility that TAFs, which are very stably associated with TBP in the holo-TFIID complex, dissociate during electrophoresis, we incubated the complexes formed in the presence of $\mathrm{Zta}$ with a polyclonal mouse serum raised against human $\mathrm{TAF}_{\mathrm{II}} 250$ (Ruppert et al. 1993; generously supplied by E.H. Wang and R. Tjian, University of California, Berkeley). Subsequent electrophoresis showed a supershift of the complex formed in the presence of holo-TFIID (lane 8) but not TBP (lane 9). Control antisera did not supershift complexes formed with holo-TFIID (not shown). Consequently, $\mathrm{TAF}_{\mathrm{II}} 250$ is in the Zta-holo-TFIID-TFIIA EMSA complex; the other TAFs are probably also present. The recently solved TBP-TATA box DNA complex structure shows that the DNA is sharply bent and kinked by TBP (J.L. Kim et al. 1993; Y. Kim et al. 1993). The slow mobility of the holoTFIID and TBP DNA complexes relative to the complex of seven $\mathrm{Zta}$ dimers $(\sim 420 \mathrm{kD})$ in this gel system is probably the result of the distortion in DNA structure produced by TBP binding. The large difference in protein mass between holo-TFIID and TBP apparently has little additional effect on mobility. This may also account for the failure of TFIIA and TFIIB binding to produce a significant change in the mobility of the holo-TFIID complex in this gel system (Fig. 2).

\section{Zta stimulates TAF-dependent DNA-protein interactions near and downstream \\ from the transcription start site}

DNase I footprinting of the Z-D-A complex revealed a strong DNase I hypersensitive site at +12 , weaker, but clear, hypersensitive sites at $-6,-2$, and +2 , and protection in the region from +14 to +28 , in addition to the footprint over the TATA box (Fig. 3B, lane 6; Fig. 4A, lane 4). Changes in the DNase I digestion pattern downstream from the TATA box were observed previously on the adenovirus major late promoter in experiments with TFIID alone using partially purified TFIID (Sawadogo and Roeder 1985) as well as highly purified holo-TFIID (Zhou et al. 1992). Because TBP does not produce the downstream footprint or hypersensitive sites on the major late promoter, we suggested that they were the result of interactions between downstream DNA and TAFs (Zhou et al. 1992). Neither partially purified TFIID preparations nor highly purified holo-TFIID alone produce downstream footprints or hypersensitive sites on the $\mathrm{E} 4$ promoter region analyzed here (Horikoshi et al. 1988a,b; Zhou et al. 1992). However, bound activator proteins induce downstream protections and hypersensitive sites by partially purified TFIID on the E4 promoter (Horikoshi et al. 1988a,b). Because we observed similar changes in the DNase I digestion pattern using highly purified holo-TFIID, Zta, and TFIIA (Fig. 3B, lane 6; Fig. 4A, lane 4), we tested whether TAFs or TFIIA participate in the formation of these downstream DNA-protein interactions.

To test whether TAFs are required for the downstream protection and hypersensitivity, footprinting was performed after binding saturating amounts of Zta, TFIIA, and either holo-TFIID or TBP (Fig. 3C). Hypersensitive sites and downstream protection were observed with holo-TFIID (lane 2) but not TBP (lane 3). We conclude that TAFs are required for these downstream DNA-protein interactions to occur.

The influence of $\mathrm{Zta}$ and TFIIA on these downstream DNA-protein interactions was analyzed in Figure 3A. Concentrations of holo-TFIID alone sufficient to produce a clear footprint over the TATA box did not produce the downstream hypersensitive sites or protections (lane 3). Similarly, addition of sufficient TFIIA to extend the holo-TFIID footprint in the upstream direction did not produce the downstream changes (lane 4). However, the combination of $\mathrm{Zta}$ and holo-TFIID did produce the hypersensitive sites and partial protection in the region from +14 to +28 (lane 5). Addition of TFIIA accentuated the hypersensitive sites (lane 6). $\Delta \mathrm{Zta}$ in combination with holo-TFIID or with holo-TFIID plus TFIIA failed to induce either the hypersensitive sites or the downstream footprint (data not shown). We conclude that the $\mathrm{Zta}$ activation domain stimulates a TAF-dependent interaction between promoter DNA and protein in the region near and downstream from the transcription start site.

\section{The $Z-D-A$ stable complex forms rapidly}

To test whether Zta affects the rate as well as the extent of holo-TFIID and TFIIA assembly on promoter DNA, we assayed complex formation as a function of time by agarose gel EMSA (Fig. 6A). TFIIA and holo-TFIID were incubated with the $Z_{7} E_{4} T$ promoter probe either in the absence (lanes 1-4) or the presence (lanes 5-8) of Zta. Four identical samples were incubated at $30^{\circ} \mathrm{C}$ for 1,5 , 15 , or $30 \mathrm{~min}$ and immediately loaded onto a running agarose gel. In the absence of $\mathrm{Zta}$, the amount of complex 

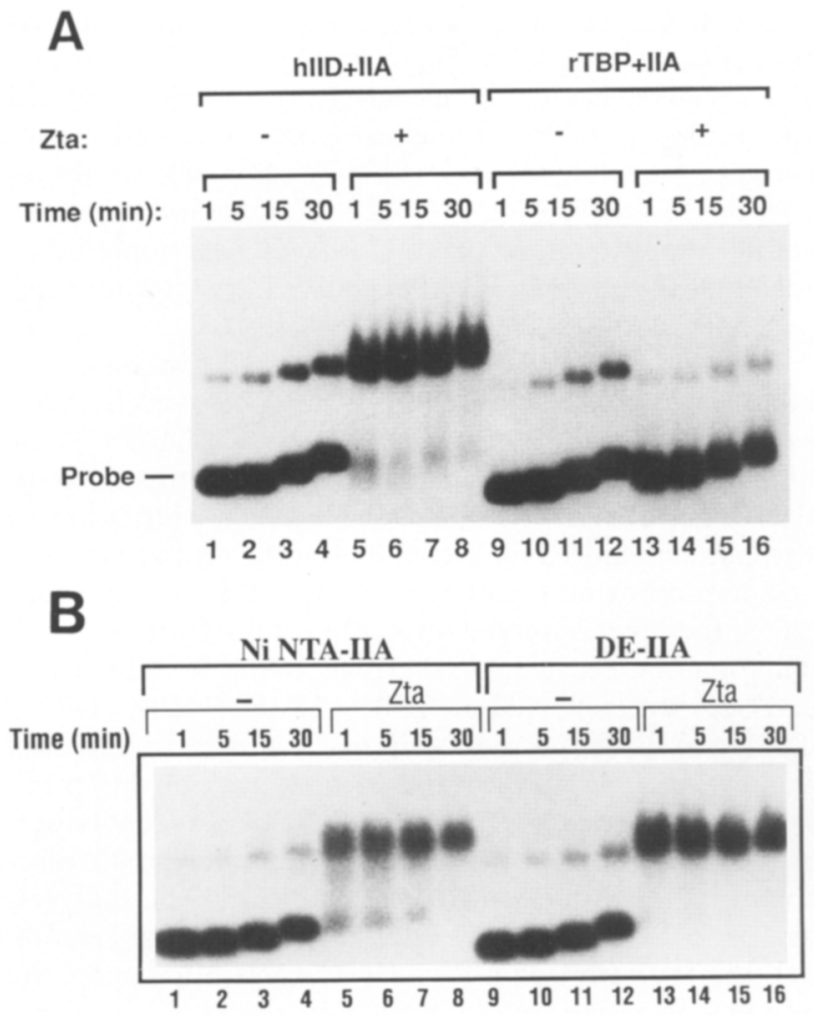

Figure 6. Zta and TFIID TAFs function together to increase the rate of TFIID-TFIIA-promoter complex formation. (A) HoloTFIID and TFIIA (0.5 unit each) were incubated alone (lanes 1-4) or with 1 unit of $Z$ ta (lanes 5-8). Reactions were incubated at $30^{\circ} \mathrm{C}$ for $1,5,15$, or $30 \mathrm{~min}$, as indicated above each lane. Alternatively, $10 \mathrm{ng}$ of $\mathrm{rTBP}$ and 0.5 unit of TFIIA were incubated alone (lanes 9-12) or with 1 unit of Zta (lanes 13-16). Reactions were loaded onto a running gel after the incubation times indicated above each lane. (B) Holo-TFIID (0.5 units) was incubated with 0.5 unit of TFIIA purified by $\mathrm{Ni}$ affinity column chromatography (Ma et al. 1993) (lanes 1-8) or 0.5 unit of the DE-IIA fraction (lanes 9-16) in the absence (lanes 1-4,9-12) or presence (lanes 5-8,13-16) of 1 unit of Zta. Reactions were loaded onto a running gel after the times indicated above each lane.

observed increased slowly over $15 \mathrm{~min}$. In contrast, in the presence of Zta, nearly all of the probe was bound in the retarded complex after only 1 min of incubation (lane 5). Consequently, formation of a Z-D-A complex stable to electrophoresis occurs rapidly compared with the slower formation of EMSA complex observed in the absence of $\mathrm{Zta}$. Moreover, TAFs are required for the rapid formation of the stable $Z-D-A$ complex, because rapid complex formation was not observed in reactions where TBP was substituted for holo-TFIID (lanes 9-16). At the 1-min time point, the stimulation of stable complex formation by $Z$ ta is striking.

The experiments presented above were performed with highly purified holo-TFIID, purified recombinant $Z$ ta, and partially purified TFIIA. To determine whether the Zta stimulation of stable complex formation requires components of the partially purified TFIIA fraction in addition to TFIIA, we repeated the binding time-course experiment using highly purified TFIIA. TFIIA was purified extensively by affinity chromatography on a $\mathrm{Ni}$ NTA column using a procedure based on the discovery from cDNA cloning that the largest of the three TFIIA subunits contains seven consecutive histidine residues (DeJong and Roeder 1993; Ma et al. 1993). This extensively purified TFIIA preparation (Ni NTA-IIA) yielded similar results to the partially purified TFIIA preparation (DE-IIA) (Fig. 6B). Slightly less mobility shift complex was formed at the early time points with the highly purified TFIIA compared with the partially purified TFIIA. This may have been because the activity of the highly purified fraction is less stable to storage at $-70^{\circ} \mathrm{C}$ than the partially purified fraction (P. Lieberman and A. Berk, unpubl.), so that somewhat less TFIIA activity was added to the reactions with affinity-purified TFIIA. Still, it is clear that addition of $\mathrm{Zta}$ produced a striking increase in the amount of complex formed at each time point in reactions using highly purified Zta, holo-TFIID, and TFIIA.

Rapidly formed $Z-D-A$ complexes are an intermediate in the assembly of functional transcription complexes

We performed the transcription experiments shown in Figure 7 to test whether the rapidly assembled Z-D-Apromoter complex observed by agarose gel EMSA can function as an intermediate in the assembly of an active transcription complex. Zta is a potent activator in a reconstituted transcription reaction using highly purified holo-TFID, recombinant TFIIB, recombinant Zta, and partially purified fractions of TFIIA; RNA polymerase II, TFIIE, TFIIF; and USA (Meisterernst et al. 1991) (Fig. 7A). We included the USA fraction in these experiments because we found that it increased $\mathrm{Zta}$ activated transcription approximately fivefold in this reconstituted in vitro transcription system (P. Lieberman and A. Berk, unpubl.). In the experiment of Figure $7 \mathrm{~B}$, a plasmid template containing the $\mathrm{Z}_{7} \mathrm{E}_{4} \mathrm{~T}$ promoter region (Fig. 1) was incubated for $1 \mathrm{~min}$ with a subset of the factors required for activated transcription (initial factors). A hundredfold molar excess of a 29-bp synthetic duplex DNA containing the adenovirus E1B TATA box (TATA-oligo) was then added and incubated for $29 \mathrm{~min}$ to bind any holoTFIID that had not bound to promoter DNA during the initial 1-min incubation. Control DNA-binding and transcription reactions demonstrated that this concentration of TATA-oligo inhibited further binding by holoTFIID to template DNA and transcription from a subsequently added template. The remaining general transcription factors required for transcription, RNA polymerase II and Zta, if not in the initial incubation, were then added along with nucleotides, and transcription was allowed to proceed for $5 \mathrm{~min}$. Zta was included in all transcription reactions because little transcription is observed in its absence (Fig. 7A).

If the stable Z-D-A complexes formed during $1 \mathrm{~min}$ of incubation (Fig. 6) can be further assembled into functional initiation complexes, we would expect to observe 


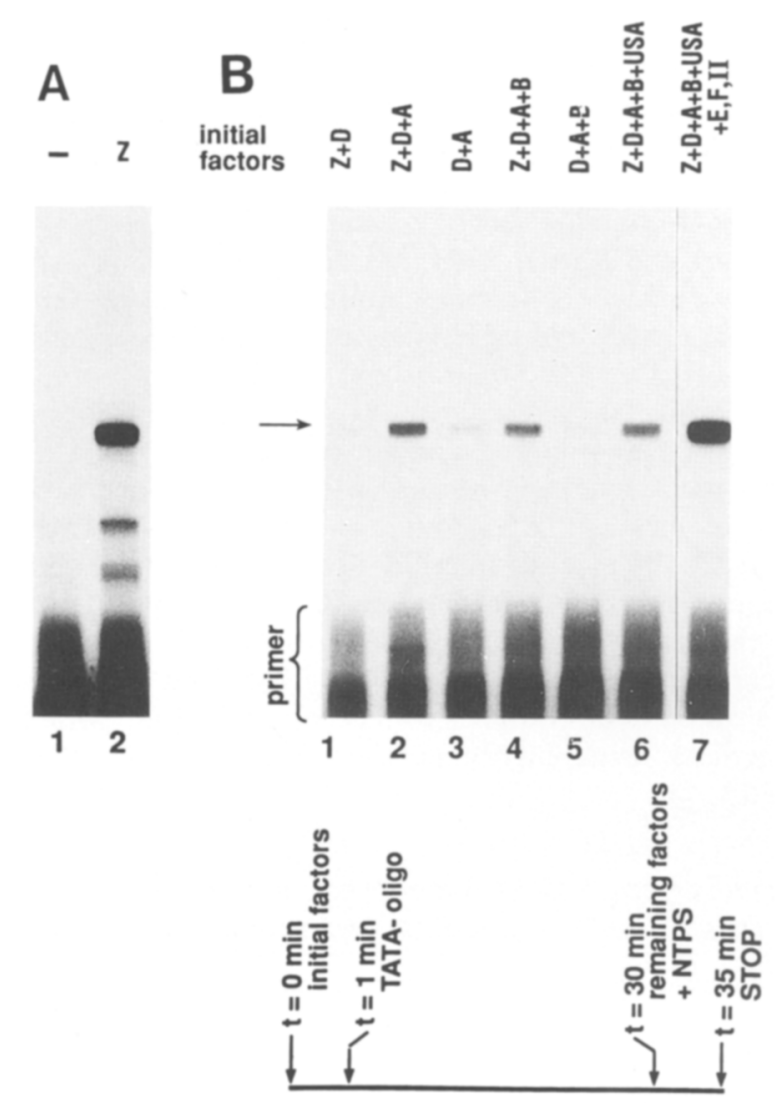

Figure 7. The rapidly formed Z-D-A complex can be further assembled into a functional, activated preinitiation complex. (A) In vitro transcription of $\mathrm{pZ}_{7} \mathrm{E}_{4} \mathrm{TCAT}$ in the absence (lane 1) and presence (lane 2) of 1 unit of $Z$ ta. Transcription was assayed by primer extension. The slowest mobililty band in lane 2 represents correctly initiated transcripts. $|B|$ The $p Z_{7} \mathrm{E}_{4}$ TCAT template was incubated with factors, TATA box-containing doublestranded DNA oligonucleotide, and nucleotide triphosphates as indicated in the time line (bottom). Initial protein fractions indicated above each lane were incubated with template for $1 \mathrm{~min}$ at $30^{\circ} \mathrm{C}$ : Zta (Z), holo-TFIID (D), DE-IIA (A), recombinant TFIIB (B), fraction E, F, II containing RNA polymerase II and the remaining factors required for basal transcription (E, F, II), and the USA fraction (USA) prepared as described (Meisterernst et al. 1991). A 100-fold molar excess (compared with $\mathrm{pZ}_{7} \mathrm{E}_{4} \mathrm{~T}$ ) of a 29-bp double-stranded oligonucleotide containing the E1B TATA box was then added, and incubation was continued for 29 $\mathrm{min}$. The protein fractions that were not added during the initial incubation were then added along with nucleotide triphosphates, and incubation was continued for $5 \mathrm{~min}$ before addition of SDS to stop transcription. The complete set of protein fractions were added at time 0 to the reaction analyzed in lane 7 . Products were analyzed by primer extension. The arrow indicates the position of correctly initiated transcripts.

transcription from the template when the remaining factors and nucleotides were added. Transcription was observed when the template was preincubated for $1 \mathrm{~min}$ with Zta, holo-TFIID, and TFIIA (Fig. 7B, lane 2). Far less transcription resulted following initial incubation with only Zta and holo-TFIID (Fig. 7B, lane 1). Consequently, this transcription assay confirmed the requirement for
TFIIA in the Zta stimulation of stable complex formation observed by EMSA (Fig. 2) and DNase I footprinting (Fig. 3B). The results of the transcription assay paralleled the results of stable complex assembly assayed by agarose gel EMSA (Fig. 2): Zta + holo-TFIID + TFIIA >> holoTFIID + TFIIA $>$ Zta + holo-TFIID. We conclude that the stable complexes assayed by EMSA are functional intermediates in the assembly of an active transcription complex.

Addition of TFIIB did not significantly increase the amount of stable complex formed, as assayed by transcription, over that formed by Zta + holo-TFIID + TFIIA alone (Fig. 7B, cf. lanes 2 and 4) nor did the further addition of the USA fraction (lane 6). However, addition of all the factors required for activated transcription to the initial preincubation stimulated transcription to about four times the level observed with Zta + holo-TFIID + TFIIA. This may be because factors that assemble onto to the Z-D-A complex (TFIIB, TFIIF, TFIIE, TFIIH, TFIIG/ TFIIJ, and RNA polymerase II) had a longer time to bind in reaction 7 ( $35 \mathrm{~min}$ ) compared with reaction 2 (5 $\mathrm{min}$ ). Alternatively, a factor in the TFIIE, TFIIF, RNA polymerase II fraction may further stimulate stable complex formation. Nonetheless, three different types of analyses, agarose gel EMSA (Fig. 2), DNase I footprinting (Fig. 3B), and the transcription assay of Figure $7 \mathrm{~B}$, all support the conclusion that the $\mathrm{Zta}$ activation domain stimulates the assembly of a Z-D-A-promoter complex that is an intermediate in the assembly of an activated transcription complex. Moreover, TFIIA is required for $\mathrm{Z}$ ta to stimulate promoter binding by holo-TFID.

\section{Discussion}

A mechanism for the functional interaction of TAFs and an activation domain in transcriptional stimulation: enhanced assembly of an activator$D-A$-promoter complex

Both TFIID-associated TAFs and activation domains are required for transcriptional stimulation by activator proteins. The results presented here demonstrate that the combination of TAFs and the $\mathrm{Zta}$ activation domain enhance (Fig. 3B) and stabilize (Fig. 4) the rapid formation (Fig. 6) of a Zta-TFIID-TFIIA-promoter DNA complex. The fact that both TAFs (Fig. 5B) and an activation domain (Fig. 5A) are required for $Z$ ta to stimulate assembly of this stable complex argues that this process is a significant aspect of the Zta activation mechanism. Rapidly assembled stable Zta-TFIID-TFIIA complexes were able to associate with the remaining general transcription factors and RNA polymerase II to support activated transcription (Fig. 7).

Recent studies of the kinetics of Zta-activated transcription indicated that $\mathrm{Zta}$ increases the rate with which TFIIA associates with the preinitiation complex (Chi and Carey 1993). TFIIA assembly into the preinitiation complex was also implicated as the rate limiting step that is enhanced by the acidic activator GAL4-AH (Wang et al. 1992). In those studies preincubation of Zta 
or GAL4-AH with TFIIA, partially purified TFIID, and promoter DNA decreased a lag in transcription initiation that was observed without the preincubation. Our results are fully consistent with these earlier studies. However, our analysis demonstrates that the stimulation of TFIIA binding is actually part of a more complex process in which the simultaneous binding of both TFIIA and TFIID is stimulated by the Zta activation domain via a mechanism requiring TFIID TAFs. To our knowledge this is the first report of an activation domain stimulating the simultaneous binding of TFIID and TFIIA. The process occurs with highly purified components (Fig. 6B) and is therefore likely to be the result of a direct effect of the $\mathrm{Zta}$ activation domain and of the TFIID TAFs.

\section{Multiple steps in transcriptional activation}

It appears that there are several different specific mechanisms by which activation domains stimulate transcription. Here, we have shown that the Zta activation domain stimulates the formation of a TFIID-TFIIA-promoter complex that nucleates the assembly of a complete, functional, activated preinitiation complex (Fig. 7). Activation domains have been shown to stimulate additional steps in preinitiation complex assembly. GAL4$\mathrm{AH}$ was shown to enhance promoter binding of TFIIB in reactions with partially purified TFIID (Lin and Green 1991) and purified recombinant TBP (Choy and Green 1993). Several activators were shown to stimulate stable promoter binding of TFIIB, TFIIF, RNA polymerase II, and TFIIE in an unfractionated nuclear extract containing all the general transcription factors and potential coactivators (Choy and Green 1993).

In addition to the stimulation of stable Z-D-A complex assembly, we observed that Zta and holo-TFID produced a DNase I footprint downstream from the transcription start site in the +14 to +28 region and hypersensitive sites near the transcription start site. This is similar to hypersensitive sites and downstream footprints produced by activators GAL4 and ATF in earlier studies of the E4 promoter with partially purified fractions of TFIID (Horikoshi et al. 1988a,b). Because the changes in DNA-protein interactions detected by these alterations in the DNase I cleavage pattern occur in the region where the TFIIF-RNA polymerase II complex and TFIIE bind (Buratowski et al. 1989), it is possible that they contribute to the activation domain and TAF-dependent increase in the binding of these factors observed by Choy and Green (1993). The results shown here (Fig. 3) demonstrate that these DNA-protein interactions require the Zta activation domain and TFIID TAFs, as they were observed with purified Zta and holo-TFIID but not with $\triangle \mathrm{Zta}$ nor TBP. Because earlier studies indicated that TAFs extend the holo-TFIID footprint in the downstream direction from the TATA box (Zhou et al. 1992) and the Zta-binding sites are upstream of the TATA box (Fig. 1), it seems likely that the DNA-protein interactions detected by the DNase I hypersensitive sites and downstream protection are the result of an interaction between one or more of the TAFs and promoter DNA.
Transcriptional activators are likely to influence the activity of preinitiation complexes by one or more of the following mechanisms: First, there is increasing evidence that activators stimulate preinitiation complex assembly by enhancing the formation of intermediate complexes in the assembly pathway through direct interactions with general transcription factors /see references in Choy and Green 1993). Second, activators might increase the rate of transcription initiation by the fully assembled preinitiation complex by interacting directly with the polymerase or indirectly by inducing a conformational change in a general transcription factor or TAF that then interacts with the polymerase. Third, a regulatory protein might bind a coactivator that stimulates transcription initiation. The results shown here demonstrate that the Zta activator both stimulates the formation of an intermediate in the assembly of an activated transcription complex and induces a conformational change in the intermediate /as evidenced by the downstream footprint) that could influence the binding of subsequent components of the transcription complex or the frequency of initiation by the fully assembled complex.

\section{A model for the stable $Z-D-A$ complex}

In addition to stimulating the amount of complex formed by TFIID and TFIIA (Fig. 3B), Zta stabilized the Z-D-A complex compared with the D-A complex. Figure 4 demonstrated that approximately half of the D-A complexes initially formed dissociated during electrophoresis in the EMSA assay. The TFIID-promoter DNA complex dissociated at an even faster rate, similar to the dissociation of the yeast TBP-TATA box complex studied earlier (Hoopes et al. 1992). In contrast, the Z-D-A complex was stable to electrophoresis. A model to account for the increased stability of the Z-D-A complex is diagramed in Figure 8 . The increased stability of the Z-D-A complex compared with the D-A complex is likely to be the result of additional DNA-protein and protein-protein interactions. Additional DNA-protein interactions in the Z-D-A complex compared with the D-A complex include the interaction between the Zta DNA-binding domain and its binding sites and the activation domain-induced downstream TFIID-DNA interaction. Additional protein-protein contacts in the Z-D-A complex compared with the D-A complex likely include the interaction between the $\mathrm{Zta}$ activation domain and the TBP subunit of TFIID (Lieberman and Berk 1991). Because TAFs and TFIIA are required for formation of the stable Z-D-A complex, additional contacts may occur between the $Z$ ta activation domain, TAFs, and TFIIA. Recently, one of the Drosophila TFIID TAFs was shown to bind to TFIIA (Yokomori et al. 1993). One function of the TAFs, then, may be to provide additional interacting protein surfaces that accelerate and stabilize TFIID and TFIIA binding to promoter DNA in response to an activation domain, as shown here for $\mathrm{Zta}$. A second function may result from the activator-induced interactions of TAFs with the initiation site and downstream region as shown by the downstream footprint and the 
Figure 8. A model for the Z-D-A complex. Observed DNA-protein interactions and demonstrated, and postulated protein-protein interactions are summarized in these diagrams. The upper TFIIDTFIIA-promoter-complex results in a DNase I footprint over the TATA box and the region just upstream from the TATA box (Fig. 3A, lane 4). Contacts between TBP and TAFs, TBP and TFIIA, and TFIIA and a TAF (Yokomori et al. 1993) are represented. The lower Zta-TFIID-TFIIA complex results in DNase I protections over the Zta-binding sites (ZRE), TATA box and upstream region, and downstream region from +14 to +28 and hypersensitive sites (arrows) at -6 to +12 (Fig. 3). The demonstrated contact between the $\mathrm{Zta}$ activation domain and TBP (Lieberman and Berk 1991) is represented, as well as postulated contacts between the activation domain, TAFs, and TFILA.

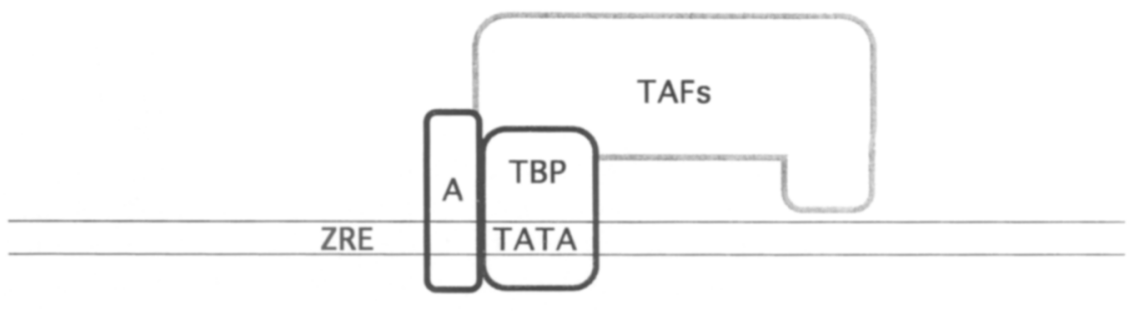

prominent DNase I hypersensitive sites that surround the site of transcription initiation.

\section{Materials and methods}

Preparation of proteins

Holo-TFIID was prepared as described (Zhou et al. 1992). One unit of holo-TFIID was defined as the amount required to shift $10 \%$ of the input probe in $\mathrm{Mg}^{2+}$ agarose gel EMSA and was equal to $0.5-2 \mu \mathrm{l}$ of the undiluted holo-TFIID fractions used in these studies. TFIIB and TBP were purified from engineered Escherichia coli as described (Zhou et al. 1992). One unit of TFIIB was defined as the amount that saturated Zta-mediated transcription in vitro (Zhou et al. 1992) in a reaction with 1 unit of holo-TFIID, and it amounted to $50 \mathrm{ng}$ of the purified TFIIB protein. Zta was purified from the M15 strain of $E$. coli transformed with $\mathrm{pH}_{6} \mathrm{Zta}$, which was constructed by inserting the $\mathrm{Zta}$ protein-coding region into the BamHI site of pQE8 (QIAGEN). The $\Delta Z$ ta expression plasmid was constructed by inserting the $\mathrm{Zta}$-coding region beginning at residue 141 into pQE8. Both $\mathrm{Zta}$ and $\Delta \mathrm{Zta}$ were purified from $E$. coli by extraction in 6 $\mathrm{M}$ guanidine- $\mathrm{HCl}, 0.1 \mathrm{M} \mathrm{Na}$ phosphate, $0.01 \mathrm{M}$ Tris- $\mathrm{HCl} / \mathrm{pH}$ $8.0), 5 \mathrm{~mm} \beta$-mercaptoethanol, and purified over Ni NTA affinity columns under denaturing conditions as described by the manufacturer (QIAGEN). Zta and $\Delta Z$ ta were renatured directly on the Ni NTA columns by washing column bound proteins in 10 column volumes of $P$ buffer $(0.1 \mathrm{M} \mathrm{Na}$ phosphate at $\mathrm{pH} 8.0$, $0.1 \mathrm{M} \mathrm{KCl}, 5 \mathrm{~mm} \beta$-mercaptoethanol) containing $8 \mathrm{M}$ urea, followed by $\mathrm{P}$ buffer containing $2 \mathrm{M}$ and then $1 \mathrm{M}$ urea, all at room temperature, then $\mathrm{P}$ buffer without urea at $4^{\circ} \mathrm{C}$. Proteins were eluted in P buffer at pH 5.9 and dialyzed into buffer D $/ 20 \mathrm{~mm}$ HEPES at $\mathrm{pH} 7.9,20 \%$ glycerol, $100 \mathrm{~mm} \mathrm{KCl}$, and $5 \mathrm{~mm} \beta$-mercaptoethanol) at $4^{\circ} \mathrm{C}$ for $6 \mathrm{hr}$ with at least three buffer changes. One unit of $\mathrm{Zta}$ and $\Delta \mathrm{Zta}$ was defined as the amount that produced complete footprinting of all seven $\mathrm{Zta}$-binding sites on 6 fmoles of the $Z_{7} E_{4} T$ promoter probe in a $25-\mu l$ reaction and amounted to $125 \mathrm{ng}$ of purified $\mathrm{Zta}$ and $67.5 \mathrm{ng}$ of $\Delta \mathrm{Zta}$.

TFIIA was purified from HeLa cell nuclear extracts. Fifteen milligrams of protein was loaded per milliliter of Whatman P-11 in buffer $\mathrm{D}$. The flowthrough fraction was then loaded onto
DE52 $15 \mathrm{mg}$ of protein $/ \mathrm{ml}$ of resin. After washing with $5 \mathrm{col}$ umn volumes of buffer $D$, TFIIA activity was eluted with a $100-500 \mathrm{~mm} \mathrm{KCl}$ gradient in buffer D. TFIIA activity was assayed by the ability to stimulate TBP binding to a TATA oligonucleotide probe in polyacrylamide gel EMSA and for the ability to support $\mathrm{Zta}$-mediated transcriptional activation in vitro (Zhou et al. 1992). Peak TFIIA fractions eluted at $\sim 320 \mathrm{~mm} \mathrm{KCl}$. Active fractions, designated DE-IIA, were dialyzed into buffer $D$. One unit equals $0.375 \mu \mathrm{g}$ of protein. Where indicated, TFIIA was further purified from the DE-IIA fraction as described (Ma et al. 1993).

\section{DNA-binding assays}

Protein-DNA-binding reactions were performed in $12.5 \mu \mathrm{l}$ of binding buffer (12.5 mM HEPES at $\mathrm{pH} 7.9,12.5 \%$ glycerol, $5 \mathrm{~mm}$ $\mathrm{MgCl}_{2}, 70 \mathrm{~mm} \mathrm{KCl}, 0.2 \mathrm{~mm}$ EDTA, and $10 \mathrm{~mm} \beta$-mercaptoethanol containing $0.5 \mathrm{mg} / \mathrm{ml}$ of BSA, $20-40 \mu \mathrm{g} / \mathrm{ml}$ poly $(\mathrm{dGdC})$, and $\sim 6 \mathrm{fmoles}$ of DNA probe. The $\mathrm{Z}_{7} \mathrm{E}_{4} \mathrm{~T}$ probe was prepared by filling in the HinDIII site with $\left[{ }^{32} \mathrm{P}\right] \mathrm{dATP}$ and cutting with EcoRI to generate a 224-bp fragment from the promoter of $\mathrm{pZ}_{7} \mathrm{E}_{4}$ TCAT (Carey et al. 1992). Binding was at $30^{\circ} \mathrm{C}$ for $60 \mathrm{~min}$ or as indicated. Gels for EMSA analysis were cast with $1.4 \%$ low EEO-agarose, containing $\mathrm{l} \times$ buffer $\mathrm{G}(45 \mathrm{~mm}$ Tris- $\mathrm{HCl}, 45 \mathrm{~mm}$ boric acid at $\mathrm{pH} 8.3,0.5 \mathrm{mM}$ EDTA, and $5 \mathrm{~mm}$ magnesium acetate). Gels were run in buffer $\mathrm{G}$ at $50 \mathrm{~V}$ for $4 \mathrm{hr}$; the gel shown in Figure 4 was run for $3 \mathrm{hr}$. Tracking dyes were not added as they inhibit DNA binding by Zta. Gels were dried on DE81 paper and exposed to Kodak XAR film for autoradiography. DNase I footprinting was as described (Lieberman and Berk 1991).

\section{In vitro transcription}

One hundred nanograms of the $\mathrm{pZ}_{7} \mathrm{E}_{4}$ TCAT (Carey et al. 1992) plasmid was incubated with the indicated fractions at $30^{\circ} \mathrm{C}$ in $25 \mu \mathrm{l} 60 \mathrm{mM} \mathrm{KCl}, 6 \mathrm{~mm} \mathrm{MgCl} 2,0.1 \mathrm{mM}$ EDTA, $12.5 \mathrm{~mm}$ HEPES at pH 7.9, $12.5 \%$ glycerol, and $5 \mathrm{~mm} \beta$-mercaptoethanol. HoloTFIID, TFIIB, and TFIIA (DE-IIA) were purified as described above and the E, F, II (Zhou et al. 1992) and USA (Meisterernst et al. 1991) fractions as described. After $1 \mathrm{~min}, 100 \mathrm{ng}$ of a 29-bp 
duplex TATA box from the adenovirus E1B promoter (Zhou et al. 1992) was added. After an additional $29 \mathrm{~min}$, all factors not added initially were added along with $400 \mu \mathrm{M}$ of the four nucleoside triphosphates and incubation was continued for $5 \mathrm{~min}$. Transcription was terminated, and specific transcripts were assayed by primer extension as described (Zhou et al. 1992).

\section{Acknowledgments}

This work was supported by grant CA 252235 from the National Cancer Institute, U.S. Public Health Service. P.M.L. was supported by a fellowship from the Leukemia Society of America.

The publication costs of this article were defrayed in part by payment of page charges. This article must therefore be hereby marked "advertisement" in accordance with 18 USC section 1734 solely to indicate this fact.

\section{References}

Abmayr, S.M., J.L. Workman, and R.G. Roeder. 1988. The pseudorabies immediate early protein stimulates in vitro transcription by facilitating TFID: Promoter interactions. Genes \& Dev. 2: 542-553.

Berger, S.L., B. Pina, N. Silverman, G.A. Marcus, J. Agapite, J.L. Regier, S.J. Triezenberg, and L. Guerente. 1992. Genetic isolation of ADA2: A potential transcriptional adaptor required for function of certain acidic activation domains. Cell 70: 251-265.

Boyer, T.G. and A.J. Berk. 1993. Functional interaction of adenovirus E1A with holo-TFIID. Genes \& Dev. 7: 1810-1823.

Buratowski, S., S. Hahn, L. Guarente, and P.A. Sharp. 1989. Five intermediate complexes in transcription initiation by RNA polymerase II. Cell 56: 549-561.

Carey, M., J. Kolman, D.A. Katz, L. Gradoville, L. Barberis, and G. Miller. 1992. Transcriptional synergy by the Epstein-Barr virus transactivator Zebra. J. Virol. 66: 4803-4813.

Chi, T. and M. Carey. 1993. The ZEBRA activation domain: Modular organization and mechanism of action. Mol. Cell. Biol. 13: 7045-7055.

Choy, B. and M.R. Green. 1993. Eukaryotic activators function during multiple steps of preinitiation complex assembly. Nature 366: 531-536.

Croston, G.E., L.A. Kerrigan, L.M. Lira, D.R. Marshak, and J.T. Kadonaga. 1991. Sequence-specific antirepression of histone H1-mediated inhibition of basal RNA polymerase II transcription. Science 251: 643-649.

DeJong, J. and R.G. Roeder. 1993. A single cDNA, hTFIIA/a, encodes both the p35 and p19 subunits of human TFIIA. Genes \& Dev. 7: 2220-2234.

Dynlacht, B.D., T. Hoey, and R. Tjian. 1991. Isolation of coactivators associated with the TATA-binding protein that mediate transcriptional activation. Cell 66: 563-576.

Flanagan, P.M., R.J. Kelleher, H. Sayre, H. Tschochner, and R. Kornberg. 1991. A mediator required for activation of RNA polymerase II transcription in vitro. Nature 350: 436-438.

Flemington, E.K., A.M. Borras, J.P. Lytle, and S.H. Speck. 1992. Characterization of the Epstein-Barr virus BZLF1 protein transactivation domain. J. Virol. 66: 922-929.

Geisberg, J.V., W.S. Lee, A.J. Berk, and R.P. Ricciardi. 1994. The zinc finger region of the E1A transactivating domain complexes with the TATA box-binding protein. Proc. Natl. Acad. Sci. 91: 2488-2492.

Gill, G. and R. Tjian. 1992. Eukaryotic coactivators associated with the TATA box binding protein. Curr. Opin. Genet. Dev. 2: 236-242.
Giot, J.F., I. Mikaelian, M. Buisson, E. Manet, I. Jacob, J.C. Nicolas, and A. Sergeant. 1990. Transcriptional interference between the EBV transcriptional factors EBI and R: Both DNAbinding and activation domains of EB1 are required. Nucleic Acids Res. 19: 1251-1258.

Goodrich, J.A., T. Hoey, C.J. Thut, A. Admon, and R. Tjian. 1993. Drosophila $\mathrm{TAF}_{\mathrm{II}} 40$ interacts with both a VP16 activation domain and the basal transcription factor TFIIB. Cell 75: 519-530.

Greenblatt, J. 1991. Roles of TFIID in transcriptional initiation by RNA polymerase II. Cell 66: 1067-1070.

Ha, I., W.S. Lane, and D. Reinberg. 1991. Cloning a human gene encoding the general transcription initiation factor IIB. $\mathrm{Na}$ ture 352: 689-695.

Hahn, S., S. Buratowski, P. Sharp, and L. Guarente. 1989. Identification of a yeast protein homologous in function to the mammalian general transcription factor IIA. $E M B O \quad$. 8: 3379-3382.

Hernandez, N. 1993. TBP, a universal eukaryotic transcription factor? Genes \& Dev. 7: 1291-1308.

Hoey, T., R.O. Weinzierl, G. Fill, J.-L. Chen, B.D. Dynlacht, and R. Tjian. 1993. Molecular cloning and functional analysis of Drosophila TAF110 reveal properties expected of coactivators. Cell 72: 247-260.

Hoopes, B.C., J.F. LeBlanc, and D.K. Hawley. 1992. Kinetic analysis of yeast TFID-TATA box complex formation suggests a multi-step pathway. J. Biol. Chem. 267: 11539-11547.

Horikoshi, M., M.F. Carey, H. Kakidani, and R.G. Roeder. 1988a. Mechanism of action of a yeast activator: Direct effect of GAL4 derivatives on mammalian TFIID-promoter interactions. Cell 54: 665-669.

Horikoshi, M., T. Hai, Y.-S. Lin, M.R. Green, and R.G. Roeder. 1988b. Transcription factor ATF interacts with the TATA factor to facilitate establishment of a preinitiation complex. Cell 54: 1033-1042.

Horikoshi, N., K. Maguire, A. Kralli, E. Maldonado, D. Reinberg, and R. Weinman. 1991. Direct interaction between adenovirus ElA protein and the TATA box binding transcription factor IID. Proc. Natl. Acad. Sci. 88: 5124-5128.

Ingles, C.J., M. Shales, W.D. Cress, S.J. Triezenberg, and J. Greenblatt. 1991. Reduced binding of TFIID to transcriptionally compromised mutants of VP16. Nature 351: 588-590.

Kim, J.L., D.B Nikolov, and S.K. Burley, 1993. Co-crystal structure of TBP recognizing the minor groove of a TATA element. Nature 365: 520-527.

Kim, Y., J.H. Geiger, S. Hahn, and P.B. Sigler. 1993. Crystal structure of a yeast TBP/TATA-box complex. Nature 365: 512-520.

Koleske, A.J., S. Buratowski, M. Nonet, and R.A. Young. 1992. A novel transcription factor reveals a functional link between the RNA polymerase II CTD and TFIID. Cell 69: 883894.

Lee, W.S., C.C. Kao, G.O. Bryant, X. Liu, and A.J. Berk. 1991. Adenovirus ElA activation domain binds the basic repeat in the TATA box transcription factor. Cell 67: 365-376.

Lieberman, P.M. and A.J. Berk. 1991. The Zta trans-activator protein stabilizes TFIID association with promoter DNA by direct protein-protein interaction. Genes \& Dev. 5: 24412454.

Lin, Y.-S. and M.R. Green. 1991. Mechanism of action of an acidic transcriptional activator in vitro. Cell 64: 971-981.

Liu, X., C.W. Miller, P.H. Koeffler, and A.J. Berk. 1993. The p53 activation domain binds the TATA box-binding polypeptide in holo-TFIID, and a neighboring p53 domain inhibits transcription. Mol. Cell. Biol. 13: 3291-3300.

Ma, D., H. Watanabe, F. Mermelstein, A. Admon, K Oguri, X. 
Sun, T. Wada, T. Imai, T. Shiroya, D. Reinberg, and H. Handa. 1993. Isolation of a cDNA encoding the largest subunit of TFIIA reveals functions important for activated transcription. Genes \& Dev. 7: 2246-2257.

Meisterernst, M., A.L. Roy, H.M. Lieu, and R.G. Roeder. 1991. Activation of regulatory gene transcription by regulatory factors is potentiated by a novel activity. Cell 66: 981-994.

Parvin, J.D., H.Th.M. Timmers, and P.A. Sharp. 1992. Promoter specificity of basal transcription factors. Cell 68: 1135-1144.

Ptashne, M. and A.A.F. Gann. 1990. Activators and targets. Nature 346: 329-331.

Pugh, B.F. and R. Tjian. 1992. Diverse transcriptional functions of the multisubunit eukaryotic TFIID complex. I. Biol. Chem. 267: 679-682.

Ranish, J.A., W.S. Lane, and S. Hahn. 1992. Isolation of two genes that encode subunits of the yeast transcription factor IIA. Science 255: 1127-1129.

Roberts, S.G., I. Ha, E. Maldonado, D. Reinberg, and M.R. Green. 1993. Interaction between an acidic activator and transcription factor TFIIB is required for transcriptional activation. Nature 363: 741-744.

Roeder, R.G. 1991. The complexity of eukaryotic transcription initiation: Regulation of preinitiation complex assembly. Trends Biochem. Sci. 16: 402-408.

Ruppert, S., E.H. Wang, and R. Tjian. 1993. Cloning and expression of human $\mathrm{TAF}_{11}$ 250: A TBP-associated factor implicated in cell-cycle regulation. Nature 362: 175-179.

Sawadogo, M. and R.G. Roeder. 1985. Interaction of a genespecific transcription factor with the adenovirus late promoter upstream of the TATA box region. Cell 43: 165-175.

Stringer, K.F., C.J. Ingles, and J. Greenblatt. 1990. Direct and selective binding of an acidic transcriptional activation domain to the TATA-box factor TFIID. Nature 345: 783-786.

Wang, W., J.D. Gralla, and M. Carey. 1992. The acidic activator GAL4-AH can stimulate polymerase II transcription by promoting assembly of a closed complex requiring TFIID and TFIIA. Genes \& Dev. 6: 1716-1727.

Workman, J., I. Taylor, and R. Kingston. 1991. Activation domains of stably bound Gal4 derivatives alleviate repression of promoters by nucleosomes. Cell 64: 533-544.

Yokomori, K., A. Admon, J.A. Goodrich, J.-L. Chen, and R. Tjian. 1993. Drosophila TFIIA-L is processed into two subunits that are associated with the TBP/TAF complex. Genes \& Dev. 7: 2235-2245.

Yoshinaga, S.K., C.L. Peterson, I. Herskowtiz, and K.R. Yamamoto. 1992. Roles of SWI1, SWI2, and SWI3 proteins for transcriptional enhancement by steroid receptors. Science 258: 1598-1604.

Zawel, L. and D. Reinberg. 1993. Initiation of transcription by RNA polymerase II: A multi-step process. Prog. Nucleic Acid Res. Mol. Biol. 44: 67-108.

Zhou, Q., P.M. Lieberman, T.G. Boyer, and A.J. Berk. 1992. Holo-TFID supports transcriptional stimulation by diverse activators and from a TATA-less promoter. Genes \& Dev. 6: 1964-1974. 


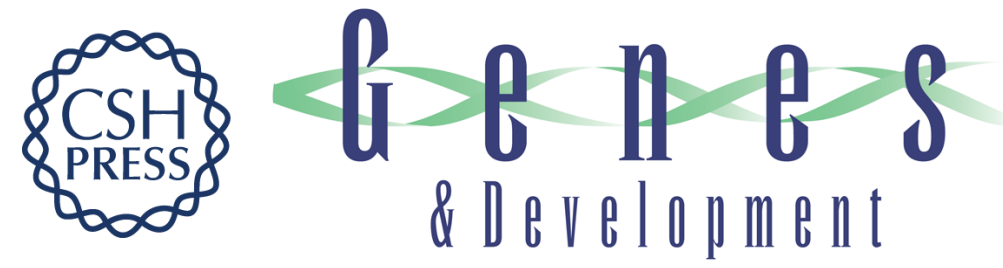

\section{A mechanism for TAFs in transcriptional activation: activation domain enhancement of TFIID-TFIIA--promoter DNA complex formation.}

P M Lieberman and A J Berk

Genes Dev. 1994, 8:

Access the most recent version at doi:10.1101/gad.8.9.995

$\begin{array}{ll}\text { References } & \begin{array}{l}\text { This article cites } 50 \text { articles, } 20 \text { of which can be accessed free at: } \\ \text { http://genesdev.cshlp.org/content/8/9/995.full.html\#ref-list-1 }\end{array}\end{array}$

License

Email Alerting Receive free email alerts when new articles cite this article - sign up in the box at the top Service right corner of the article or click here.

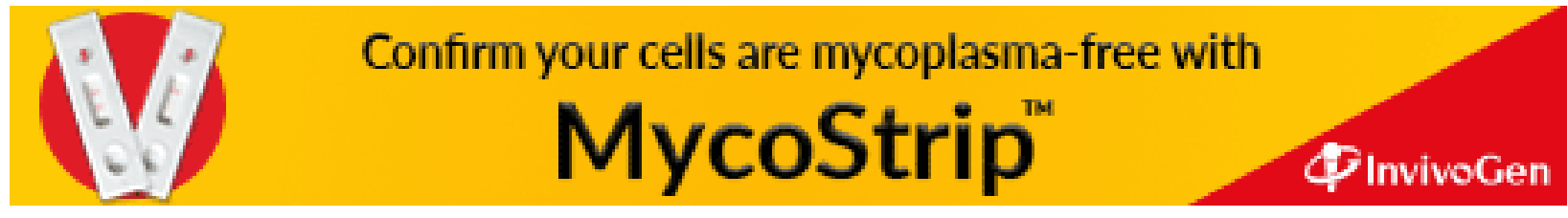

